Document downloaded from:

http://hdl.handle.net/10251/64311

This paper must be cited as:

Navarro Campos, C.; Aguilar Martí, MA.; Garcia Marí, F. (2012). Aggregation pattern, sampling plan, and intervention threshold for Pezothrips kellyanus in citrus groves. Entomologia Experimentalis et Applicata. (142):130-139. doi:10.1111/j.15707458.2011.01204.x.

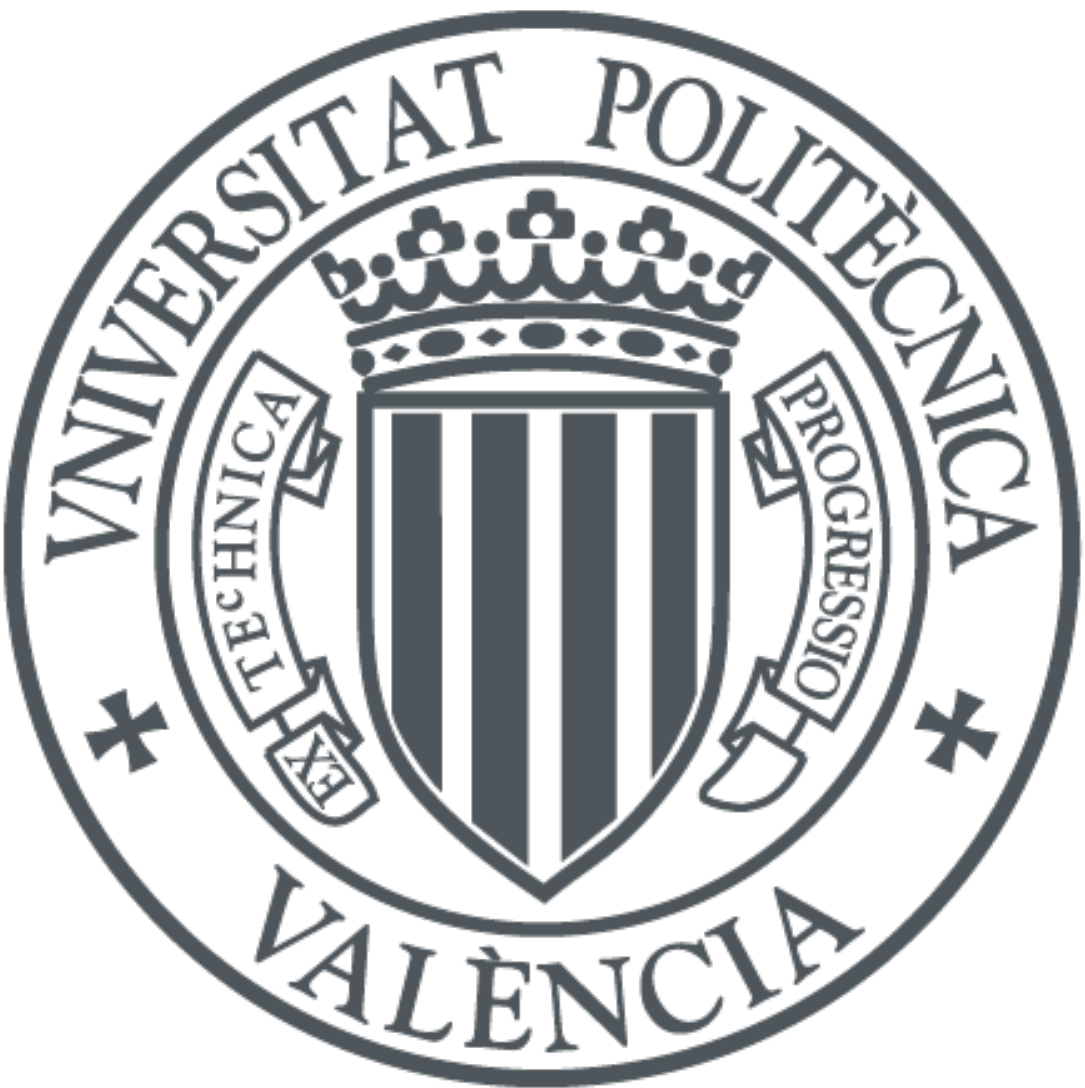

The final publication is available at

https://dx.doi.org/10.1111/j.1570-7458.2011.01204.x

Copyright Wiley

Additional Information 


\title{
Aggregation Pattern, Sampling Plan and Intervention Threshold for Pezothrips kellyanus in Citrus Groves
}

\author{
C. Navarro-Campos, A. Aguilar \& F. Garcia-Marí.
}

Instituto Agroforestal Mediterráneo (IAM), Universidad Politécnica de Valencia, Camino de Vera s/n, 46022, Valencia, Spain.

Correspondence: crinacam@posgrado.upv.es, fgarciam@eaf.upv.es

Short Title: Aggregation and sampling plan for thrips in citrus

Key words: aggregation, monitoring, sample size, EIL, EEIL, larvae description, Taylor’s power law, KCT, Frankliniella occidentalis, citrus thrips, Thripidae, Thysanoptera 


\section{Abstract}

Pezothrips kellyanus (Bagnall) (Thysanoptera: Thripidae) has recently emerged as an international pest of citrus. It causes severe scarring of the fruit surface and commercial downgrading of fresh fruit production. The goals of this paper were to determine the aggregation patterns of $P$. kellyanus on citrus, to establish an efficient sampling plan to assess their population density, and to develop an environmental economic injury level. The study was conducted in 14 citrus groves in Valencia (Spain) during 2008 and in eight citrus groves during 2009. On each grove, population densities of thrips were monitored weekly on citrus flowers and fruitlets during the flowering and fruit setting period. Final damage was determined on developed fruits. Pezothrips kellyanus was the most abundant thrips species, with $73.5 \%$ of adults and 92.1\% of larvae present, followed by Frankliniella occidentalis (Pergande) (Thysanoptera: Thripidae), with $18.2 \%$ and 3.5\%, respectively. First description of first and second larvae of $P$. kellyanus is provided. Our results prove that thrips show clumped population distributions, with no differences in aggregation parameters between flowers and fruitlets, thrips species, larval stages or sex of adults. Immature thrips showed a higher aggregation (Taylor's value of $b=1.40 \pm 0.06)$ than adults $(b=1.19 \pm 0.04)$. Fruit damage by $P$. kellyanus on developed fruits was strongly correlated $(r=0.8968 ; n=22)$ with number of fruitlets with immature $P$. kellyanus. Based on the percentage of fruitlets occupied by immature thrips the economic injury levels (EIL) and environmental economic injury levels (EEIL) were calculated (using chlorpyrifos as insecticide) obtaining values of $7 \%$ and $12 \%$, respectively. Insecticide treatments will be necessary if more than $12 \%$ of fruitlets are infested by thrips larvae. Constant precision $(\mathrm{D}=0.25)$ sampling plans developed show that 200 sample units should be observed in 
enumerative sampling, and 310 in binomial presence-absence sampling, at population levels of immatures on fruitlets around the EEIL.

\section{Introduction}

Thrips (Thysanoptera: Thripidae) are common insects that feed on a wide variety of plants and are frequently found associated with citrus (Quayle, 1941; Lewis, 1997). A great number of thrips species have been recorded on citrus trees, but only relatively few species are serious crop pests (Bodenheimer, 1951; Childers \& Nakahara, 2006; Costa et al., 2006).

Kelly’s Citrus Thrips (Pezothrips kellyanus (Bagnall), thereafter KCT) became a serious pest of citrus fruits during the last decade in southern Australia, New Zealand and several countries of the Mediterranean Basin namely Italy, Greece, Portugal, Turkey, Cyprus and Spain (Blank \& Gill, 1997; Marullo, 1998; Mound \& Jackman, 1998; Orphanides, 1998; Conti et al., 2001; Varikou et al., 2002; Franco et al., 2006; Vassiliou, 2007; Navarro et al., 2008). KCT is a flower-living species and its abundance in citrus groves peaks in spring during the main flowering period (Baker et al., 2002). Adults need to establish on flowers for breeding purposes (Blank \& Gill, 1997). KCT causes a ring of scar tissue around the calyx and rind blemish on young and mature fruit (Blank \& Gill, 1997; Baker, 2006). Most of the rind damage to fruitlets is apparently caused by larvae (Blank \& Gill, 1997; Navarro-Campos et al., 2011). In cases of serious damage, the scarring can cover the entire fruit (Vassiliou, 2010). The period of greatest risk of injury occurs during the first four to five weeks after petal fall (Baker et al., 2002). The feeding activities of these arthropods cause no substantial degradation of the tissues consumed by humans (Hare, 1993), but have a major economic impact on fresh fruit production, as they downgrade the external appearance of the fruit, reducing or eliminating its market value (Gilbert \& Bedford, 1998). 
At the moment, the basic problem remains on how to control KCT (as well as other citrus thrips) effectively without destroying the very important natural enemy complex of scale insects, mealybugs, mites and other citrus pests (Gilbert \& Bedford, 1998). In that context, integrated pest management (IPM) is based on the idea that chemical control should only be used as a last resort. The decision to apply chemical insecticides is taken only when the population exceeds the economic injury levels (EIL). The EIL is defined as the lowest population density that will cause economic damage. Economic damage begins to occur when the cost (in terms of money) of suppressing insect-caused injury is equal to the potential monetary loss from a pest population (Stern et al., 1959; Pedigo, 1999). The EIL indicates when the management of a pest is economically justified, but does not provide users with information of choosing the least environmentally hazardous pesticide when a pesticide must be used. Another intervention threshold, the environmental EIL (EEIL), incorporates both economic criteria and environmental risk criteria for IPM decision making (Higley \& Winstersteen, 1996).

Thus, it is necessary to develop a methodology for sampling KCT populations and to obtain an EIL in order to facilitate decision-making regarding the management of this pest. Sampling programs are dependent on knowledge of the spatial distribution of the population being sampled (Kuno, 1991). Up to date, there is limited information available about the above aspects for KCT due to its recent appearance as an international pest (Vassiliou, 2010). Intervention thresholds have been established for other species of citrus thrips like Scirtothrips citri Moulton and Scirtothrips aurantii Faure. Flint et al. (1991) recommended a threshold level of 5-10\% of fruits with presence of $S$. citri larvae. Regarding S. aurantii, treatment threshold was determined for using yellow traps as monitoring system (Samways et al., 1986; Grout \& Richards, 1990). Subsequently, Grout and Stephen (2000) and Moore et al. (2008) refered a fruit 
infestation of $2 \%$ on oranges by $S$. aurantii larvae as an intervention threshold during the first 4 weeks after petal fall. In the case of KCT, direct fruit counting seems to be the best method for management decision-making (Conti et al., 2003; Baker, 2006; Perrotta \& Conti, 2008). Monitoring of 100 fruits has been recommended in several technical documents (Baker, 2006; Jackman et al., 2011) and chemical treatment is recommended if more than 5-10\% of fruits are occupied by thrips larvae (Perrotta et al., 2004; Baker, 2006). Nevertheless, these recommendations were not based on statistical data analysis.

Consequently, the goals of this paper were to determine the aggregation pattern of KCT on citrus trees, to develop an efficient and statistically accurate sampling plan to assess population changes, to relate thrips population density and economic damage and to establish an EEIL for KCT in order to reduce crop vulnerability to this pest.

\section{Materials and methods}

Sampling Groves. The study was conducted in 14 groves in 2008 and eight groves in 2009. All of the groves were commercial citrus plantations situated in an extensive citrus monoculture region in the south of the city of Valencia, Spain. The eight groves sampled in 2009 included four groves sampled the year 2008 and four new groves. The groves were located in areas where high damage by KCT was observed the previous year. Groves were selected trying to cover different environmental characteristics, as sampling plans should be developed from robust data sets covering the geographic area of the taxa and encompassing the range of environmental conditions likely to be encountered for particular species in specific environments (Naranjo \& Hutchison, 1997). The groves were of sweet orange (Citrus sinensis (L.) Osbeck) (including the varieties Valencia late (four groves) Navel Lane late (six groves) and Navelina (two groves)), Clementine mandarin (Citrus reticulata Blanco) (two groves) and the hybrid Ortanique $(C$. 
sinensis (L.) x C. reticulata) (four groves). All the groves had normally developed 11 to 15-yrold trees in full production. Their surface area ranged from 0.5 ha to 2 ha. The groves had not been treated with pesticides for at least six months before sampling and were not treated during the sampling period.

Sampling procedure. On each grove, fifty open fresh citrus flowers or fruitlets, (five per tree from 10 trees), were haphazardly collected around the tree canopy. This sampling was repeated weekly from late March until the end of June during the two years of the study. Each flower or fruitlet sampled was immediately placed individually inside a plastic recipient containing 10ml of $70 \%$ ethanol. In the laboratory, flowers and fruitlets were carefully searched and all postembrional development stages of thrips were extracted and counted under a stereomicroscope. In total, 259 samples of 50 sample units per sample were collected: 107 samples of flowers and 152 samples of fruitlets.

Thrips identification. Adults and larvae were identified on the basis of the descriptions of Mound \& Walker (1982) and Milne et al. (1997). Only a brief description of second-instar larvae of KCT is published by Kirk (1987), thus larvae of this species were identified by using our own keys based on progeny reared from KCT adults. Recently, during the redaction of this manuscript, a new key of second instar larvae of the Thripidae, with $P$. kellyanus included, has been published by Veirbergen et al. (2010). Nevertheless, first instar larvae were not included. According to our keys, first larvae (L1) of KCT was characterized by having the abdominal segment IX dorsally with a sclerotised band from the posterior margin to at least the insertion of setal pairs 1 and 2, which are knobbed. This abdominal segment presents several rows (from 4 to 5) in addition to the posterior comb. The abdominal segment X of L1 presents a sclerotised band extending from the posterior margin to at least the insertions of setal pairs 1 and 2. Finally, 
presence of minute microtriquia is other characteristic of this segment. Second larvae (L2) weres characterized by having one dorsal pair and two ventral pairs of large teeth laterally in the comb on the posterior margin of abdominal segment IX. Both abdominal segments, IX and X, are similar than segments of L1 in having sclerotised bands but different in the absence of rows of microtriquia (see Navarro et al. (2009) for images of the abdominal segments).

Dispersion Pattern. Aggregation indices were calculated using Taylor's power law (Taylor, 1961) and Iwao’s patchiness regression (Iwao, 1968). Taylor's power law relates mean density to variance by the equation: $s^{2}=a m^{b}$, where $s^{2}$ is the sample variance, $m$ is the sample mean density, and $a$ and $b$ are Taylor's coefficients. The coefficient $a$ is a scaling factor related to sample size and $b$ is the Taylor's index of aggregation. A simple regression after log-log transformation $\left(\log s^{2}=\log a+b \log m\right.$ ) is used to estimate the coefficients. Iwao's patchiness regression, $m^{*}=\alpha+\beta$, $\mathrm{m}$ is based on the relationship of Lloyd's index of mean crowding $\left(m^{*}\right)$ to mean density $(m): m^{*}=m+\left[\left(\mathrm{s}^{2} / m\right)-1\right]$ (Lloyd, 1967). The intercept $(\alpha)$ is an index of basic contagion and the slope $(\beta)$ has the same meaning as $b$ in the Taylor's power law. The goodnessof-fit of the linear model was evaluated by the estimation of $r^{2}$. Two-tailed $t$-tests ( $\mathrm{df}=n-2, \alpha=$ 0.05) were used to determine if the slopes of regression lines were significantly different from 1.0. Values of $b$ over groves, years of sampling, thrips life stages and sample units were compared using 95\% confidence interval.

Taylor's and Iwao's coefficients were calculated separately for each thrips life stage sampled (L1, L2, adult males and adult females) and thrips species (KCT and Frankliniella occidentalis (Pergande) (Western Flower Thrips, thereafter, WFT)). KCT indices were calculated separately in flowers and fruitlets, whereas in the case of WFT we calculated only indices in flowers because this species was almost absent from fruitlets. 
Economic injury levels. The EIL was calculated according to the formula of Norton (1976) modified by Pedigo et al. (1986): $E I L=C / V I D K$, where $C=$ cost of KCT control $(€ /$ ha), $V=$ price of the fruit on origin ( $€ /$ ha), $I=$ injury units per insect per production unit [proportion fruits scarred/(insect/ha)], $D=$ damage per unit injury [(Kg reduction/ha)/proportion fruits scarred] and $K=$ reduction of damage with treatment (i.e. efficacy of the product, $0<K<1$ ). $I^{*} D$ (yield loss per unit of pest) was obtained from the slope $b$ of the damage function: $y=a+b x$, where $y$ is the percentage of damaged fruits at harvest and $x$ is the percentage of sample units (flowers or fruitlets) infested by thrips; therefore: $E I L=C / V I D K=C / V b K$.

To obtain the damage function we calculated the correlation coefficients between fruit injury at each grove and the percentage of flowers and fruitlets occupied by adult and immature KCT in the previous flowering and fruit setting period, using Statgraphics 5.1 program (Statgraphics, 1994). The injury at each grove was obtained directly from the average percentage of fruits with severe rind damage. We considered severe rind damage when the fruit had scars consisting in a complete ring around the calyx or a substantial partial ring with other lineal scars on the fruit surface. These fruits were considered totally lost from a commercial point of view. On each grove, a random sample of 10 fruits per tree from 10 trees was taken weekly along the summer (from July to September). During this period the damage remains constant as it is produced earlier, in late spring. The relative abundance of KCT larvae and adults on each grove was calculated as the maximum percentage of sample units infested by KCT.

Enumerative Sampling. The calculation of the minimum sample size $(n)$ required to estimate density with a fixed coefficient of variation $D$ was based in the Green's method (Green, 1970), which establishes the precision of the sample considering the standard error as a fixed proportion 
$(D)$ of the sample mean. The variance was substituted by its expression according to Taylor's indices:

$$
n=a m^{(b-2)} / D^{2}
$$

We used the value of $D$ which is usually applied for extensive studies of insects populations $(D=$ 0.25) (Southwood \& Henderson, 2000).

Binomial Sampling. A binomial sampling plan was developed with the aim of estimating the thrips density by counting the number of sample units infested. This method can only be applied if we know the relationship between the proportion of sample units infested with KCT and the mean number of thrips per unit. We checked the fit of our data to the Wilson \& Room's model (1983):

$$
p=1-\exp \left(-m \ln \left(a m^{(b-1)}\right) /\left(a m^{(b-1)}-1\right)\right)
$$

where $p$ is the proportion of infested sample units, $m$ is the thrips mean density and $a$ and $b$ are Taylor's coefficients.

The sample size $(n)$ required to estimate the thrips mean density $(m)$ for a fixed relative precision $(D)$ in the presence-absence sampling was calculated using the expression of the variance proposed by Kuno (1986):

$$
n=D^{-2}\left(1-p_{0}\right) p_{0}^{-(2 / k)-1}\left[k\left(p_{0}^{-1 / k}-1\right)\right]^{-2},
$$

where $p_{o}$ is the proportion of non infested sample units and $k$ was calculated from the mean and the Taylor's indices by the equation:

$$
k=m^{2} /\left(a m^{b}-m\right) .
$$

\section{Results and discussion}

A total of 5,123 adult thrips were obtained from individually collected flowers and fruitlets of the 18 citrus groves sampled during the years 2008 and 2009. The most abundant 
species was Pezothrips kellyanus (Bagnall) (KCT) (73.5\% of the specimens), followed by Frankliniella occidentalis (Pergande) (WFT) (18.5\%), Thrips tabaci (Lindeman) (5.3\%) and Thrips major Uzel (2.1\%). Similarly, out of a total of 4,037 thrips larvae, the species proportions found were KCT (92.1\%), WFT (3.5\%), T. tabaci (2.7\%) and T. major (1.2\%). Similar proportions were found when considering the groves and years of sampling separately. In every one of the 18 groves sampled and on each of the two years KCT was the most abundant thrips species, followed by WFT.

Aggregation Indices. The two most abundant species, KCT and WFT, include 92\% of the adults sampled and $95.6 \%$ of the larvae. Although KCT is considered more important pest, WFT is often found in citrus flowers. For that reason we determined initially the aggregation indices separately for the two species. Correlation coefficients of Taylor's power law were higher and less variable than values for Iwao's regression for all development stages, species of thrips and units sampled. The coefficient of determination $\left(r^{2}\right)$ of Taylor indices ranged from 0.88 to 0.98 for KCT and from 0.70 to 0.97 for WFT. For Iwao's patchiness regression, values of $r^{2}$ ranged from 0.28 to 0.65 in KCT and from to 0.01 to 0.75 for WFT. Thus, Taylor's power law provided a consistently better fit for the relationship between the variance and the mean of thrips samples (Table 1). Therefore, only Taylor's power law parameters were used in the development of the sampling plan.

The values of the coefficient $b$ of Taylor were almost always significantly $>1$ ( $\mathrm{P}<0.01$, twotailed $t$ tests, see Table 1) (except for L1 of WFT in flowers, due probably to the low number of samples), indicating an aggregated population distribution. For each thrips species, no significant differences in the value of $b(\mathrm{P}>0.05)$ were found neither between sexes nor between the two larval stages (see Table 1). Consequently we calculated common $b$ values for both sexes in adults 
and for both immature stages in larvae. Similarly, no significant differences of the value $b$ were obtained between flowers and fruitlets $(\mathrm{P}>0.05)$ and between the two thrips species, KCT and WFT $(\mathrm{P}>0.05)$. Therefore, common values were added to Table 1.

When considering separately development stages, plant sample units and thrips species, the immature stages of thrips showed always higher $b$ values than the adults. Values of $b$ ranged from 1.31 to 1.47 for immature (L1 or L2) (excluding L1 of WFT, see above), whereas in adults (females or males) they ranged from 1.12 to 1.27 (Table 1). Similarly, when all adults or all larvae were grouped together, $b$ values were always numerically greater for larvae than for adults. The final result of the Taylor aggregation index $b$ for KCT in flowers and fruitlets together shows a value of 1.40 for larvae, significantly higher than the value of 1.19 for adults (Table 1; Figure 1).

Similar results were found by Rhodes \& Morse (1989) in Scirtothrips citri Moult in Navel oranges. They found, as in our experience, a higher value of the Taylor index $b$ for larvae ( $b=1.31)$ than for adults $(b=1.13)$. Lower dispersal activity of larvae compared to that expected by winged adults is the probable cause cited by those authors for this difference. On host plants other than citrus, several studies have analyzed the dispersion pattern of WFT populations, which change with the host plant considered. However, as in our results, when comparing immature and adult stages on the same host plant, populations of immature thrips are always more clumped than populations of adults (Steiner, 1990; Salguero-Navas et al., 1994; Wang \& Shipp, 2001; Park et al., 2009). The $b$ value of WFT in citrus flowers found in our study is considerably lower than the $b$ value observed for the same thrips species in tomato and cucumber flowers by other authors. The $b$ value of WFT is common to the $b$ value of KCT in our study and similar to the $b$ 
value for Scirtothrips citri on citrus fruitlets (Rhodes \& Morse, 1989). Thus, probably the pattern of aggregation on citrus is similar on other phytophagous thrips species as well.

It is remarkable that WFT was present in flowers but was almost absent from fruitlets. Moreover, WFT does not reproduce adequately in citrus orchards, as only $3.5 \%$ of all thrips larvae found were of WFT, whereas $18.5 \%$ of all adults identified belonged to this species. Thus, adults of WFT visit citrus flowers for feeding on pollen, but rarely reproduce on the flowers and are not attracted by the developing fruits. According to Teksam \& Tunç (2009) the only thrips that damage citrus fruit are those that feed on the developing fruits, just as, or soon after, the petals fall, not those that feed on pollen and floral tissues in the flowers. WFT is not considered a pest of citrus in Italy (Marullo 2001), Cyprus (Vassiliou 2007) or Spain (Lacasa \& Llorens 1996). It was reported as a pest in Japan (Tsuchiya et al. 1995), but its damage consisted in young fruit rot as a result of fungal infection caused by WFT infesting flowers at the end of the flowering period, not in scarring of the fruit.

Enumerative Sampling Plan. The required number of sample units (sample size) to monitor KCT was calculated using Green's sequential sampling plan at a precision level of $D=0.25$ (Figure 2). The sample size was calculated separately for adults and larvae as they show significantly different aggregation patterns. The results are equally applicable to flowers and fruitlets because it was generated from a common Taylor’s power law regression.

Binomial Sampling Plan. The determination of the relationship between insect density per sample unit and percentage of infested sample units can reduce the time of sampling as it allows estimating density without counting all insects present on each sampling unit. The model by Wilson \& Room's (1983) fits adequately the above relationship for both adult and immature KCT in flowers and fruitlets (Figure 3). The equation describes our field data well, with $r^{2}=0.96$ 
for adults and $r^{2}=0.91$ for immatures. The number of required units to be sampled in order to obtain the precision level of 0.25 (SEM/mean) when using a binomial sampling plan is showed in Figure 4.

Economic injury levels. The relationships between the percentage of damage on developed fruit and the percentage of flowers or fruitlets infested by immature or adult KCT are showed in Table 2. We included in these correlations all citrus species or varieties sampled in this work, as they showed similar trends in all cases. Higher correlation coefficients are associated with immatures and the highest value corresponds to immatures on fruitlets. Other authors had previously observed that KCT damage is produced mostly by larvae feeding on fruitlets (Blank \& Gill, 1997; Navarro-Campos et al., 2011). Consequently, EIL’s were developed for the percentage of fruitlets infested by immature KCT.

To calculate an EIL as percentage of citrus fruitlets occupied by immature KCT we used the formula: $E I L=C / V I D K=C / V b K$. The cost of control $C(285 € /$ ha $)$ was composed by cost of the product (135 €/ha) and cost of the application (150 €/ha). Monetary values were taken from published assays with chlorpyrifos (96 g/liter of water) as treatment for KCT (Collof et al., 2003; Tena et al., 2009). The price of the crop was fixed at:

$$
V=0.22 € / \mathrm{kg} * 30,000 \mathrm{~kg} / \mathrm{ha}=6,600 € / \mathrm{ha}
$$

according to official national statistics about prices on origin for navel oranges (MARM, 2011). The efficacy $(K)$ of the product chlorpyrifos in controlling KCT in oranges groves was taken as $\mathrm{K}=0.68$, an average among values obtained from two different authors (Vassiliou, 2007; Tena et al., 2009). The slope $b$ of the correlation between the maximum percentage of fruitlets infested by immature KCT and the average damage on fruits at harvest was taken from the equation on table 2 . 
$\mathrm{EIL}=C / V I D K=C / V b K=285 € / \mathrm{ha} /(6,600 € / \mathrm{ha} * 0.8968 * 0.68)=7.1$ (percentage of fruitlets infested by immature KCT).

The EEIL using chlorpyrifos as insecticide can be approximated as $1.7 *$ EIL according to Higley \& Wintersteen (1996). Therefore: EEIL = 12\% of fruits occupied by immature KCT. This percentage corresponds to a population density of 0.20 immature thrips per fruit (see Figure 3). Since economic and dynamic biological parameters determined the EIL, few studies have concentrated on the development of EIL in perennial crops after its first theoretical definition (Damos \& Savopoulou-Soultani, 2010). The IPM guidelines of the University of California recommended a threshold for treatment with sabadilla for Scirtothrips citri in Valencia oranges, of $10 \%$ infestation by immature thrips without predaceous mites, and $20 \%$ if predaceous mites are present. For navel oranges, a 5\% infestation of immatures without predaceous mites may warrant treatment and $10 \%$ when predaceous mites are present above a threshold of 0.2 predaceous mites per leaf (Flint et al., 1991).

Sample size. The estimated sample size depends on the population density of the species. According to our results, the EEIL of $12 \%$ corresponds to a population density of 0.20 immature thrips per fruit. Thus, when the population density is 0.20 thrips per sample unit, the number of units to be sampled, according to the enumerative sampling plan, would be 125 for adult thrips and 200 for immature thrips (see Figure 2). This is the minimum number of units to be sampled if we wish to attain the desired precision level of $=0.25$ at population densities around the EEIL. On the other hand, according to the binomial sampling plan, the number of units to be sampled when the population density is 0.20 thrips per unit would be 160 for adult thrips and 310 for immature thrips (see Figure 4). These sample sizes are considerably larger than earlier recommendations (Baker, 2006; Jackman et al., 2011). 
At higher population densities, fewer sample units are required. For instance, to estimate a mean density of 0.6 thrips per unit, 50 sample units are required for adults and 100 for larvae (see Figure 2).

In summary, after the study of dispersion parameters of KCT and WFT, we have shown that these phytophagous thrips have patterns of aggregation similar between species and between citrus unit sampled, flowers or fruitlets, but differing between immatures and adults. Sample sizes needed to estimate population densities for KCT and WFT in citrus flowers or fruitlets with preestablished precision levels were developed. The curves that relate sample size with thrips population, either for enumerative or presence-absence sampling, will be useful to estimate population densities of KCT or WFT from citrus flowers/fruitlets. From these results, and considering that binomial or presence-absence sampling (counting plant sample units with thrips present) is considerably easier and less time-consuming that counting all thrips on each unit, a binomial sampling plan is recommended for monitoring KCT in IPM programs to determine if the pest reaches the EEIL. Not less than 300 fruitlets should be monitored weekly from petal fall until the fruits reach $4 \mathrm{~cm}$ in diameter. Fruits $4 \mathrm{~cm}$ or larger in diameter are rarely scarred by citrus thrips (Flint et al., 1991; Blank \& Gill, 1997). Insecticide treatment will only be necessary if more than $12 \%$ of fruitlets are occupied by larvae.

\section{Acknowledgments}

We thank Apostolos Pekas for his useful comments on previous versions of the manuscript. We thank also the citrus producers who provided the orchards for the study. Finally, we are grateful to two anonymous referees for their careful review and helpful comments. The first author was awarded an FPI fellowship from the Universitat Politècnica de València to obtain her PhD degree or fulfill her PhD studies. 


\section{References}

Baker GJ, Jackman D, Keller M, MacGregor A \& Purvis S (2002) Development of an integrated pest management system for thrips in Citrus. HAL Final Report CT97007, 125.

Baker GJ (2006) Kelly citrus thrips management. Fact sheet. Government of South Australia, primary industries and resources SA.

doi: http://www.sardi.sa.gov.au/pages/ento/hort_pests/kctfact_sheet.pdf.

Blank RH \& Gill GSC (1997) Thrips (Thysanoptera:Terebrantia) on flowers and fruit of citrus in New Zealand. New Zealand Journal of Crop and Horticultural Science 25: 319-332.

Bodenheimer FS (1951) Citrus entomology in the Middle East. W. Junk. The Hague, Netherlands.

Childers CC \& Nakahara S (2006) Thysanoptera (thrips) within citrus orchards in Florida: Species distribution, relative and seasonal abundance within trees, and species on vines and ground cover plants. Journal of Insect Science 6: 1-19.

Colloff MJ, Fokstuen G \& Boland T (2003) Towards the triple bottom line in sustainable horticulture: biodiversity, ecosystem services and an environmental management system for citrus orchards in the Riverland of South Australia. CSIRO Entomology, Canberra.

Conti F, Tuminelli R, Amico C, Fisicaro R, Raciti E, Frittitta C, Perrotta G \& Marullo R (2001) Monitoring Pezothrips kellyanus on citrus in eastern Sicily. Thrips, Plants, Tospoviruses: Proceedings of the 7th International Symposium on Thysanoptera, University Reggio Calabria, Reggio Calabria, Italy, pp. 207-210.

Conti F, Tumminelli R, Fisicaro R, Perrotta G, Marullo R \& Liotta G (2003) An IPM system for new citrus thrips in Italy. Bulletin of IOBC/WPRS 26(6): 203-208. 
Costa L, Mateus C, zur Strassen R \& Franco JC (2006) Thrips (Thysanoptera) associated to lemon orchards in the Oeste region of Portugal. Bulletin of IOBC/WPRS 29(39): 285-291.

Damos P \& Savopoulou-Soultani M (2010) Population dynamics of Anarsia lineatella in relation to crop damage and the development of economic injury levels. Journal of Applied Entomology 134: 105-115.

Flint ML, Kobbe B, Clark JK, Dreistadt SH, Pehrson JE, Flaherty DL, O’Conell NV, Phillips PA \& Morse JG (1991) Integrated pest management for citrus, $2^{\text {nd }}$ ed. University of California. Oakland, CA.

Franco JC, Garcia-Marí F, Ramos AP \& Besri M (2006) Survey on the situation of citrus pest management in Mediterranean countries. Bulletin of IOBC/WPRS 29(39): 335-346.

Gilbert MJ \& Bedford ECG (1998) Citrus thrips Scirtothrips aurantii Faure. Citrus Pests in the Republic of South Africa (ed. by ECG Bedford, MA Van den Berg \& EA de Villiers) ARC-Institute for Tropical and Subtropical Crops, South Africa, pp. 164-170.

Green RH (1970) On fixed precision sequential sampling. Researches on Population Ecology 12: 249-251.

Grout TG \& Richards GI (1990) Monitoring citrus thrips, Scirtothrips aurantii Faure (Thysanoptera, Thripidae), with yellow card traps and the effect of latitude on treatment thresholds. Journal of Applied Entomology 109: 385-389.

Grout TG and Stephen PR (2000) Intervention thresholds for citrus thrips Scirtothrips aurantii on citrus fruit. SA Fruit J. 1(5): 18-19.

Hare JD (1993) Sampling arthropod pest in citrus. Handbook of sampling methods for arthropods in agriculture (ed. by LP Pedigo \& GD Buntin) CRC Press, Florida, USA, pp 417- 432. 
Higley LG \& Wintersteen WK (1996) Threshold and environmental quality. Economic thresholds for integrated pest management (ed. LG Higley \& LP Pedigo) University of Nebraska Press, Lincoln, NE, pp. 290 - 274.

Iwao S (1968) A new regression method for analyzing the aggregation pattern of animal populations. Researches on Population Ecology 10: 1-20.

Jackman D, Keller M, Baker G, MacGregor A \& Purvis S (2011) The key to controlling Kelly's citrus thrips is finding them early. South Australian Research and Development Institute. doi:http://www.sardi.sa.gov.au/pestsdiseases/horticulture/horticultural_pests/kelly_citrus_t hrips.

Kirk WDJ (1987) A key to the larvae of some common Australian Flower Thrips (Insecta, Thysanoptera), with a host-plant survey. Australian Journal of Zoology 35(2): 173-185.

Kuno E (1986) Evaluation of statistical precision and design of efficient sampling for the population estimation based on frequency of occurrence. Researches on Population Ecology 28: 305- 319.

Kuno E (1991) Sampling and analysis of insect populations. Annual Review of Entomology 36: 285-304.

Lacasa A \& Llorens JM (1996) Trips y su control biológico (I) Pisa Ediciones. Spain.

Lewis T (1997) Thrips as crops pests. CAB International. UK.

Lloyd M (1967) Mean crowding. Journal of Animal Ecology 36: 1-30.

MARM (2011) Ministerio de Medio ambiente y Medio Rural y Marino. doi: http://www.marm.es

Marullo R (1998) Pezothrips kellyanus un nuovo thripide parassita delle culture meridionali. Informatore Fytopatologico 10: 72-74. 
Marullo R (2001) Impact of an introduced pest thrips on the indigenous natural history and agricultural systems. In Thrips and Tospoviruses (R. Marullo and L. A. Mound, eds.). Proceedings of the 7th International Symposium on Thysanoptera, University of Reggio Calabria, Italy, 2001, pp. 285-288.

Milne JR, Milne M \& Walter GH (1997) A key to larval thrips (Thysanoptera) from granite belt stonefruit trees and a first description of Pseudanaphothrips achaetus (Bagnall) larvae. Australian Journal of Entomology 36: 319-326.

Moore SD, Grout TG, Hattingh V \& Hofmeyr JH (2008) Thresholds and guidelines for intervention against citrus pests. SA Fruit J. Aug/Sep: 77-81.

Mound LA \& Walker AK (1982) Terebrantia (Insecta: Thysanoptera). Fauna of New Zealand 1, 120.

Mound LA \& Jackman DJ (1998) Thrips in the economy and ecology of Australia. Proceedings of the Sixth Australian Applied Entomological Research Conference, 1: 472-478.

Naranjo SE \& Hutchison WD (1997) Validation of arthropod sampling plans using a resampling approach: software and analysis. American Entomologist 43: 48-57.

Navarro C, Aguilar A \& Garcia Marí F (2008) Pezothrips kellyanus: trips causante de daños en frutos de cítricos. Levante Agrícola 392: 298-303.

Navarro C, Aguilar A \& Garcia-Marí F (2009) Reconocimiento de inmaduros y adultos de Pezothrips kellyanus (Thysanoptera: Thripidae) y caracterización de sus daños en cítricos. Phytoma España 214: 16-17. doi: http://www.phytoma.com/uploads/reconocimiento.pdf Navarro-Campos C, Aguilar A \& Garcia-Marí F (2011) Population trend and fruit damage of Pezothrips kellyanus in citrus orchards in Valencia (Spain). Bulletin of IOBC/WPRS 62: 285-292. 
Norton GA (1976) Analysis of decision making in crop protection. Agro-Ecosystems (now Agric Ecosystems Environ) 3: 27-44.

Orphanides G (1998) Thrips on citrus. Annual Review for 1997. Agricultural Research Institute, Nicosia, Cyprus.

Park JJ, Lee DH, Shin KI, Lee JH \& Cho K (2009) Analysis of spatial and temporal associations of adult and immature Frankliniella occidentalis Pergande (Thysanoptera: Thripidae) in cucumber greenhouses. Applied Entomology and Zoology 44 (4): 569-577.

Pedigo LP, Hutchins SH \& Higley LG (1986) Economic injury levels in theory and practice. Annual Review of Entomology 31: 341-368.

Pedigo LP (1999) Entomology and Pest Management, 3rd edn. Englewood Cliffs, NJ: PrenticeHall.

Perrotta G, Fiscaro R, Vecchio S, Cartabellotta D \& Pedrotti CC (2004) Citrus thrips monitoring methods in Eastern Sicily. Proceedings of the International Society of Citriculture 3: 900903.

Perrotta G \& Conti F (2008) A threshold hypothesis for an integrated control of thrips infestation on citrus in south-Eastern Sicily. Control in Citrus Fruit Crops. Bulletin of IOBC/WPRS 38: 204-209.

Quayle HJ (1941) Insects of citrus and other subtropical fruits. Pub. Comsdtock Pub.co. Ithaca. N.Y.

Rhodes AA \& Morse JG (1989) Scirtothrips citri sampling and damage prediction on California navel oranges. Agriculture, Ecosystems and Environment 26: 117-129.

Salguero-Navas VE, Funderburk JE, Mack TP, Beshaer RJ \& Olson SM (1994) Aggregation indices and sample size curves for binomial sampling of flower-Inhabiting Frankliniella 
Species (Thysanoptera: Thripidae) on tomato. Journal of Economic Entomology 87(6): $1622-1626$.

Samways MJ (1986) Spatial distribution of Scirtothrips aurantii Faure (Thysanoptera: Thripidae) and threshold level for one per cent. Damage on citrus fruit based on trapping with fluorescent yellow sticky traps. Bulletin of Entomological Research 76: 649-659.

Southwood TRE \& Henderson PA (2000) Ecological methods, 3rd. ed. Blackwell, Oxford, England.

Statgraphics (1994) Version 5.1 Plus. Statistical graphics system by Statistical Graphics Corporation. Manugistics, Rockville, MD.

Steiner MY (1990) Determining Population Characteristics and Sampling Procedures for the Western Flower Thrips (Thysanoptera: Thripidae) and the Predatory Mite Amblyseius cucumeris (Acari: Phytoseiidae) on Greenhouse Cucumber. Environmental Entomology 19(5): 1605-1613.

Stern VM, Smith RF, van den Bosch R \& Hagen KS (1959) The integrated control concept. Hilgardia 29: 81-101.

Taylor LR (1961) Aggregation, variance and the mean. Nature (Lond.) 189: 732-735.

Tena A, Catalán J, Monzó C, Jacas J \& Urbaneja A (2009) Control químico de Pezothrips kellyanus, nueva plaga de los cítricos, y sus efectos sobre la entomofauna auxiliar. Levante Agrícola 397: 281-289.

Teksam I \& Tunç I (2009) An analysis of Thysanoptera associated with citrus flowers in Antalya, Turkey: Composition, distribution, abundance and pest status of species. Appl. Entomol. Zool. 44 (3): 455-464. 
Tsuchiya M, Togawa M, Furuhashi K \& MASUI S (1995) Infestation and damage caused by Western Flower Thrips (Frankliniella occidentalis Pergande) on satsuma mandarine (Citrus unshiu Marc). Jpn. J. Appl. Entomol. Zool. 39(3): 253-259.

Vassiliou, V. A. (2007) Chemical control of Pezothrips kellyanus (Thysanoptera: Thripidae) in citrus plantations in Cyprus. Crop Prot. 26: 1579-1584.

Varikou K, Tsitsipis JA, Alexandrakis V \& Mound L (2002) Pezothrips kellyanus (Bagnall) (Thysanoptera: Thripidae), a new pest of citrus trees in Crete. Proceedings of the VIIth European Congress of Entomology, Thessaloniki (Greece), p. 33.

Vassiliou V (2007) Chemical control of Pezothrips kellyanus (Thysanoptera: Thripidae) in citrus plantations in Cyprus. Crop protection 26: 1579-1584.

Vassiliou V (2010) Ecology and Behavior of Pezothrips kellyanus (Thysanoptera: Thripidae) on Citrus. Journal of Economic Entomology 103(1): 47-53.

Vierbergen G, Kucharczyk H \& Kirk WDJ (2010) A key to the second instar larvae of the Thripidae of the Western Palaeartic region (Thysanoptera). Tijdschrift voor Entomologie 153: 99-160.

Wang K \& Shipp JL (2001) Sequential Sampling Plans for Western Flower Thrips (Thysanoptera: Thripidae) on Greenhouse Cucumbers. Journal of Economic Entomology 94(2): 579-585.

Wilson LT \& Room PM (1983) Clumping patterns of fruit and arthropods in cotton, with implications for binomial sampling. Environmental Entomology 12: 50-54. 


\section{Figure legends}

Fig.1. Taylor’s power law regression for adult and immature Kelly’s Citrus Thrips (KCT) Pezothrips kellyanus on citrus flowers or fruitlets individually collected (50 units/sample); Combined data from 18 groves sampled during 2008 and 2009. Broken line represents expected immature KCT and solid line represents expected adult KCT.

Fig.2. Number of sample units required for sampling Kelly’s Citrus Thrips (KCT) Pezothrips kellyanus populations in citrus, based on the number of thrips per flower or fruitlet, to achieve a fixed precision level of 0.25 . The number of real samples encountered at each population density is shown in a secondary axis.

Fig.3. Relationship between the proportion of sample units infested with adult (A) and immature (B) Kelly's Citrus Thrips (KCT) Pezothrips kellyanus and the mean number of thrips per sample units. X-axis truncated at 1 (approximately 95\% of samples have a mean number of thrips per unit $<1)$.

Fig. 4. Number of sample units required for sampling Kelly’s Citrus Thrips (KCT) Pezothrips kellyanus populations in citrus, based on the percentage of flowers or fruitlets infested, to achieve a fixed precision level of 0.25 . The number of real samples encountered at each population density is shown in a secondary axis. 
Figures

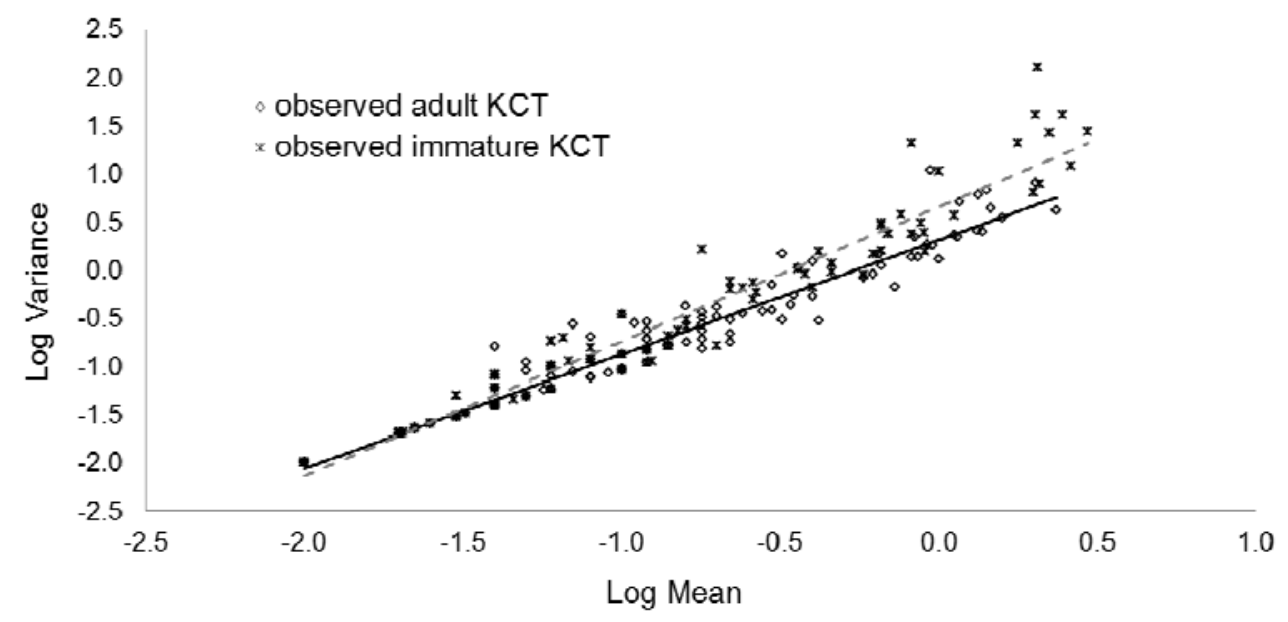

Fig. 1 


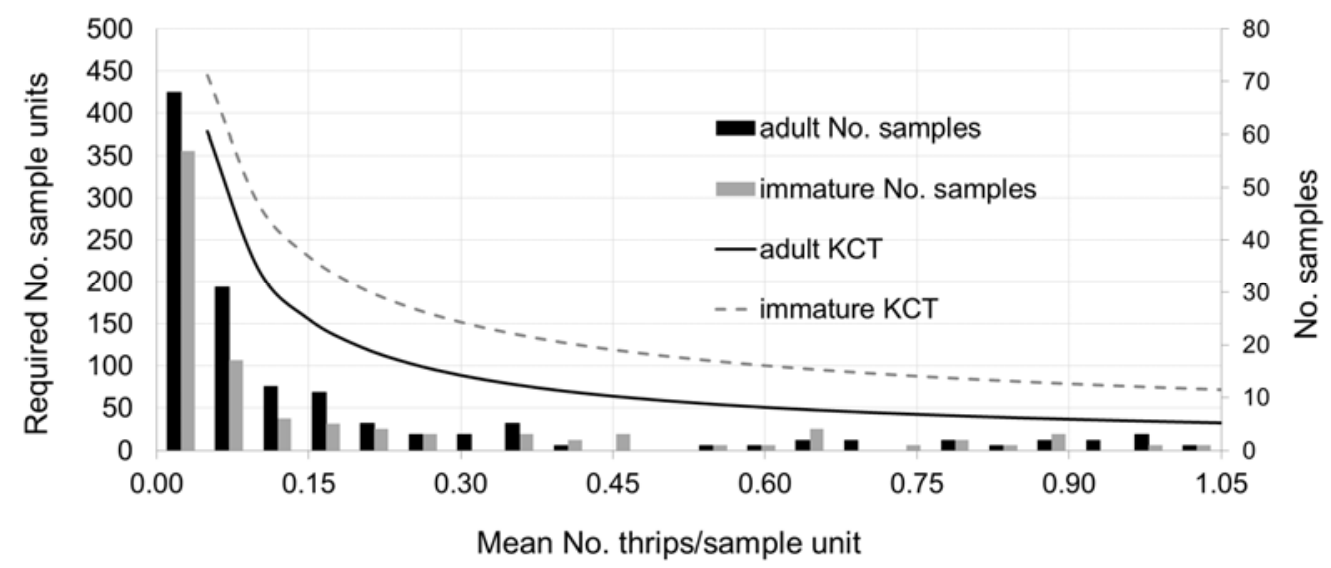

Fig. 2 

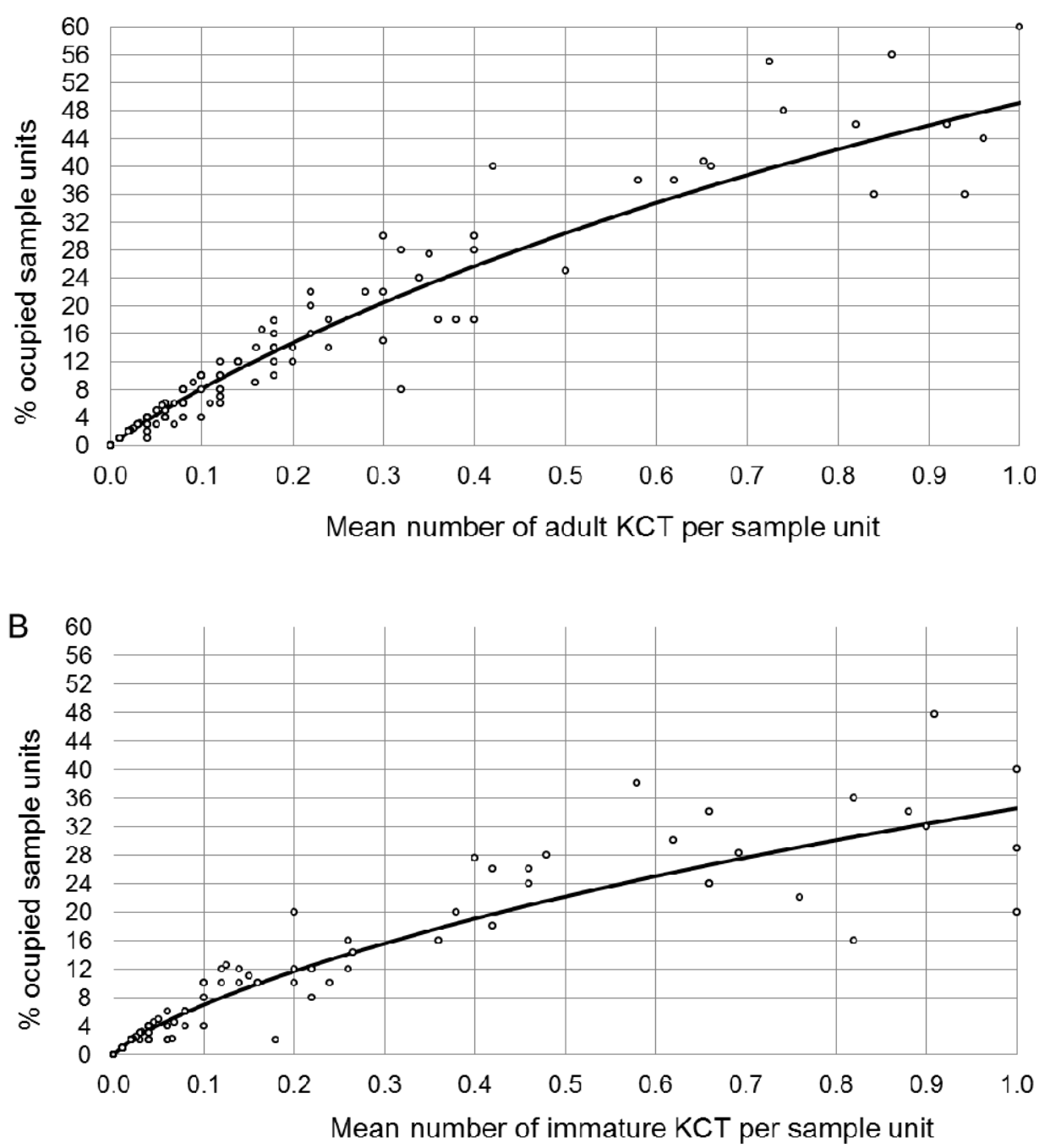

Fig. 3 


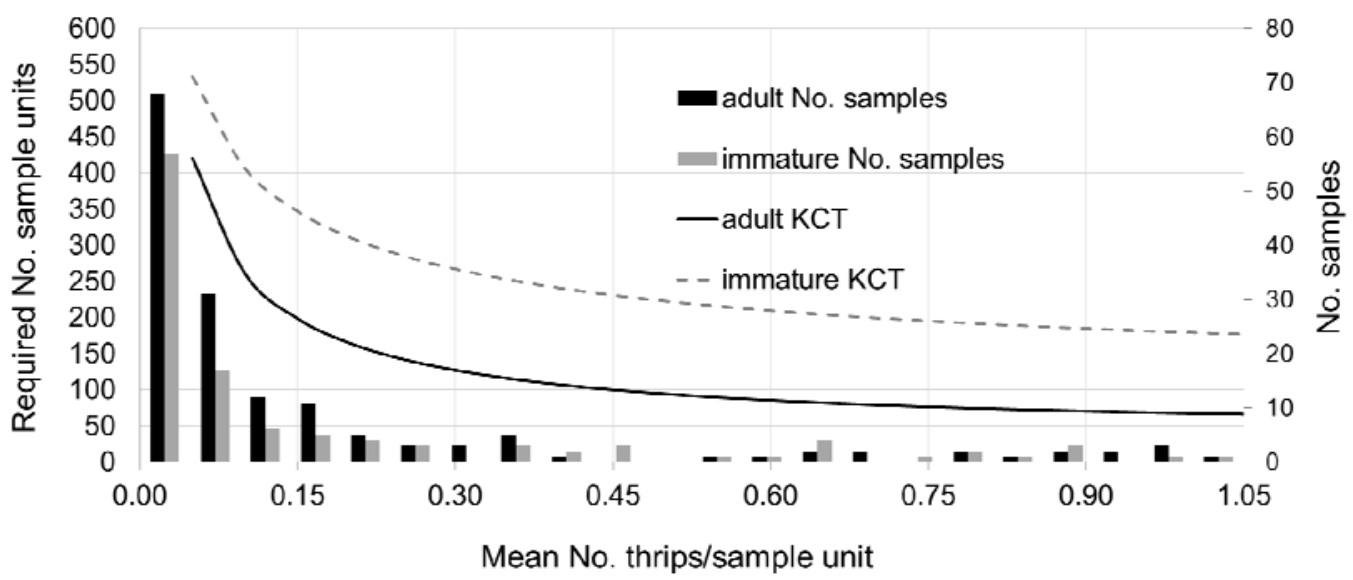

Fig. 4 


\section{Tables}

Table1. Regression statistics generated by Taylor's power law for the relationship between the variance and mean of Kelly’s Citrus Thrips (KCT) Pezothrips kellyanus and Western Flower Thrips (WFT) Frankliniella occidentalis sampled on citrus flowers and fruitlets.

\begin{tabular}{ccccccccc}
\hline \hline Species & Sample unit & Lifestage & $\boldsymbol{n}$ & $\boldsymbol{a}$ & $\boldsymbol{b}$ & $\boldsymbol{r}^{\mathbf{2}}$ & $\begin{array}{c}\text { t-value for } \\
\text { slope }=\mathbf{1}\end{array}$ & $\begin{array}{c}\text { Confidence } \\
\text { interval }(\boldsymbol{b})\end{array}$ \\
\hline KCT & flower & Female & 61 & 1.69 & 1.15 & 0.962 & 5.04 & $1.09-1.21$ \\
KCT & flower & Male & 50 & 2.90 & 1.27 & 0.968 & 8.06 & $1.20-1.34$ \\
KCT & flower & L1 & 41 & 4.25 & 1.38 & 0.946 & 7.12 & $1.27-1.48$ \\
KCT & flower & L2 & 44 & 6.12 & 1.47 & 0.943 & 8.49 & $1.36-1.59$ \\
KCT & fruitlet & Female & 81 & 2.44 & 1.22 & 0.891 & 4.65 & $1.13-1.32$ \\
KCT & fruitlet & Male & 49 & 1.63 & 1.12 & 0.976 & 4.61 & $1.07-1.17$ \\
KCT & fruitlet & L1 & 18 & 4.05 & 1.36 & 0.880 & 2.84 & $1.09-1.62$ \\
KCT & fruitlet & L2 & 59 & 3.30 & 1.31 & 0.947 & 7.53 & $1.23-1.39$ \\
WFT & flower & Female & 52 & 1.62 & 1.14 & 0.971 & 4.88 & $1.08-1.19$ \\
WFT & flower & Male & 25 & 1.69 & 1.16 & 0.957 & 3.08 & $1.05-1.26$ \\
WFT & flower & L1 & 13 & 1.78 & 1.13 & 0.699 & 0.571 & $0.64-1.61$ \\
WFT & flower & L2 & 19 & 4.01 & 1.37 & 0.887 & 3.11 & $1.12-1.61$ \\
\hline KCT & flower & Adult & 69 & 2.12 & 1.21 & 0.968 & 7.83 & $1.16-1.26$ \\
KCT & flower & Immature & 56 & 5.41 & 1.44 & 0.950 & 9.81 & $1.35-1.53$ \\
KCT & fruitlet & Adult & 91 & 2.05 & 1.18 & 0.924 & 4.92 & $1.11-1.25$ \\
KCT & fruitlet & Immature & 63 & 3.36 & 1.31 & 0.949 & 8.01 & $1.23-1.39$ \\
WFT & flower & Adult & 55 & 1.76 & 1.16 & 0.976 & 6.48 & $1.11-1.21$ \\
WFT & flower & Immature & 26 & 3.98 & 1.38 & 0.867 & 3.42 & $1.15-1.60$ \\
\hline KCT & flower+fruitlet & Adult & 160 & 2.09 & 1.19 & 0.956 & 9.31 & $1.15-1.23$ \\
KCT & flower+fruitlet & Immature & 119 & 4.61 & 1.40 & 0.952 & 13.74 & $1.34-1.46$ \\
\hline
\end{tabular}

${ }^{1}$ Indicates t-value for slope $=1(P>0.01)$

${ }^{2}$ Adults $=$ combined analysis for males + females; Immatures = data for $\mathrm{L} 1+\mathrm{L} 2$ 
Table 2. Equations relating, on each grove, the percentage of developed citrus fruits with severe scarring by Kelly's Citrus Thrips (KCT) Pezothrips kellyanus (y) with the maximum percentage of flowers or fruitlets infested by adults or immature KCT $(x)$. Data obtained from 14 groves in 2008 and eight groves in 2009.

\begin{tabular}{cccccc}
\hline Sample unit & KCT Life stage & Equation $^{1}$ & $\mathbf{r}^{2}$ & $\mathbf{n}$ & P-value \\
\hline flower & adult & $\mathrm{y}=0.3544 \mathrm{x}$ & 0.64 & 22 & $\mathrm{P}<0.0001$ \\
flower & immature & $\mathrm{y}=0.5461 \mathrm{x}$ & 0.81 & 22 & $\mathrm{P}<0.0001$ \\
fruitlet & adult & $\mathrm{y}=0.6594 \mathrm{x}$ & 0.51 & 22 & $\mathrm{P}<0.001$ \\
fruitlet & immature & $\mathrm{y}=0.8968 \mathrm{x}$ & 0.92 & 22 & $\mathrm{P}<0.0001$ \\
\hline
\end{tabular}

${ }^{1}$ The intercepts are no significantly different to zero $(\mathrm{P}>0.05)$. 